\title{
O PROGRAMA PARÁ RURAL E O DESENHO INSTITUCIONAL PARA A GOVERNANÇA
}

\author{
THE PROGRAM PARÁ RURALAND THE INSTITUCIONAL DESIGN FOR GOVERNANCE
}

\author{
Brenda Cordovil ${ }^{1}$ \\ Mário Miguel Amin ${ }^{2}$
}

\begin{abstract}
RESUMO
Esta pesquisa tem como objetivo analisar a estrutura de governança nos projetos cofinanciados pelo Programa Pará Rural, propondo-se, ao final dos trabalhos, a responder se essa estrutura é favorável ao desenvolvimento dos projetos cofinanciados pelo Banco Mundial para redução da pobreza rural no Estado do Pará, objeto do referido Programa. A teoria base utilizada é a da governança, pois se entende que os padrões de articulação e cooperação que coordenam e regulam as transações dentro do projeto são determinantes para sua execução e resultado. Também utilizará a teoria institucional e da ação coletiva, visando analisar como as diferentes condições sistêmicas se refletem na implantação dos projetos e como se expressam os elementos da ação coletiva, possibilitando, assim, o entendimento não só dos resultados dos projetos, mas também de como as relações de governança são construídas. Trata-se de uma pesquisa qualitativa, fruto da análise de documentos produzidos pelo Banco Mundial e pelo Governo do Estado do Pará, com vistas a compreender a estrutura do Programa e se ela é favorável à governança e de resultado de levantamentos realizados na Comunidade Menino Jesus, município de Acará, onde foram aplicados questionários semiestruturados e entrevistas. Como resultado, verificou-se que o desenho institucional do Programa Pará Rural aborda aspectos de governança de forma superficial, sem indicar possíveis ações e responsáveis, deixando a critério do gestor a implementação ou não de uma estratégia eficaz para a consolidação de possíveis arranjos que favoreçam os projetos.
\end{abstract}

Palavras-chave: Governança; agricultura familiar; desenvolvimento rural.

\begin{abstract}
This research aims to analyze the governance structure in co-financed projects by the Pará Rural Program, proposing at the end of the work, to answer whether this structure is favorable to the development of projects co-financed by the World Bank for rural poverty reduction in Para State, the said program object. The basic theory used is that of governance as it is understood that the standards of coordination and cooperation to coordinate and regulate transactions within the project are crucial for its implementation and results. Also use the institutional and collective action theory, aiming to analyze the different systemic conditions are reflected in the implementation of projects and how to express the elements of collective action, thus enabling the understanding not only of the results of projects, but also as

\footnotetext{
${ }^{1}$ Graduada em Administração pela Universidade Federal do Pará (UFPA). Especialista em Gerenciamento de Projetos pela Fundação Getúlio Vargas (FGV). Mestre em Administração pela Universidade da Amazônia (UNAMA). E-mail: brendacordovil@yahoo.com.br

${ }^{2}$ Graduado em Agronomia pela California State Polythecnic University (CAL POLY, EUA). Mestre e Doutor em Economia Agrícola pela University of Florida (UF, EUA). Professor do Núcleo de Altos Estudos Amazônicos da Universidade Federal do Pará (NAEA/UFPA). E-mail: marioamin@gmail.com
} 
governance relationships are built. This is a qualitative research, the result of analysis of documents produced by the World Bank and the Government of the State of Pará, in order to understand the program structure and whether it is in favor of governance and results of surveys conducted in the Community Child Jesus the municipality of Acara, where semistructured interviews and questionnaires were administered. As a result, it was found that the institutional design of the Pará Rural Program addresses governance issues in a superficial way, without indicating possible actions and responsible, leaving the manager's discretion implementation or not an effective strategy for the consolidation of possible arrangements that favor projects.

Key words: Governance; family farming; rural development

JEL: Q00; Q01; Q15

\section{Introdução}

A estratégia de incentivo a atividades produtivas no meio rural com base na agricultura familiar traz à tona um debate sobre opções capazes de promover a melhoria na qualidade de vida no campo. A ocupação rural favorece o estabelecimento de relações sociais no campo, evitando o êxodo e consequentes mazelas oriundas do inchaço das cidades, como o desemprego.

Por outro lado, no momento em que o agricultor se vê como atuante no processo de transformação da sociedade ocorre o fortalecimento do capital social. Neste contexto, o apoio à agricultura familiar vai além das atividades produtivas, visto que envolve fortalecer a gestão, o crescimento conjunto através de empreendimentos coletivos e a visão de que, pela soma de esforços e pela ajuda mútua, é possível adquirir melhores resultados para todos (ARAUJO, 2003).

É através da compreensão dos objetivos dos programas de fortalecimento da agricultura familiar voltados para a inserção produtiva das comunidades que é possível entender a importância da análise das relações entre as instituições. A interação entre a comunidade e o ambiente e com os atores determina a forma como as relações são constituídas (OLIVEIRA; SANTANA 2012).

$\mathrm{O}$ estudo de governança visa identificar os principais aspectos das relações estabelecidas entre o ambiente institucional e os atores sociais, a fim de determinar sua eficiência no que tange à redução dos seus custos de transação (OLIVEIRA; SANTANA, 
2012 apud WILLIAMSON, 1999). Estudar as relações de governança constituídas entre as comunidades beneficiadas pelos programas de apoio à agricultura familiar, cofinanciados pelo Banco Mundial, e as instituições com as quais interagem é de grande importância para a compreensão da dinâmica de organização dos arranjos de transações. Envolve também a aceitação dos pressupostos comportamentais de racionalidade limitada e oportunismo, devendo ser considerada a complexidade das relações interfirmas e das especificações dos ativos. Com o intuito de compreender a dinâmica das transações, este trabalho pretende analisar criticamente o desenho institucional do Programa Pará Rural, indicando suas implicações, a implementação e a efetividade do projeto, verificando se o desenho institucional pré-concebido era favorável ou não à boa governança dos projetos.

Este trabalho está dividido em oito tópicos, sendo que o primeiro é a introdução, o segundo a metodologia e o terceiro o marco teórico de referência, o qual irá demonstrar aspectos da teoria da governança, ação coletiva e teoria institucional. No quarto tópico será apresentando um resumo do Programa Pará Rural e no quinto uma análise do desenho institucional para a governança. Por fim o sexto trará os resultados da pesquisa na Comunidade Menino Jesus, o sétimo as conclusões e o oitavo as referências bibliográficas.

\section{METODOLOGIA}

Trata-se de uma pesquisa exploratória. Segundo Gil (2008), as pesquisas exploratórias têm como principal finalidade desenvolver, esclarecer e modificar conceitos e ideias, tendo em vista a formulação de problemas mais precisos ou hipóteses pesquisáveis para estudos posteriores. De todos os tipos de pesquisa, estas são as que apresentam menor rigidez no planejamento, envolvendo, habitualmente, levantamento bibliográfico e documental, entrevistas não padronizadas e estudos de caso. Procedimentos de amostragem e técnicas quantitativas de coleta de dados não são costumeiramente aplicados nestas pesquisas (GIL, 2008).

Será utilizado o método qualitativo, que considera uma relação dinâmica entre o mundo real e o sujeito, isto é, um vínculo indissociável entre o mundo objetivo e a subjetividade do sujeito, que não pode ser traduzido em números, sendo o processo e seu significado os focos principais de abordagem (SILVA; MENEZES, 2002).

O foco inicial deste trabalho é a análise de documentos produzidos pelo Banco Mundial e pelo Governo do Estado do Pará, objetivando compreender a estrutura do Programa, de modo 
a verificar se ela é favorável à governança. Será feita uma reflexão sobre o desenho institucional concebido para o Pará Rural à luz do referencial teórico adotado.

Será apresentado o resultado de levantamentos feitos na Comunidade Menino Jesus, município de Acará, estado do Pará, onde serão aplicados questionários semiestruturados e entrevistas ao presidente da cooperativa e à equipe de cooperados responsável pela administração do empreendimento.Tendo como referência estes questionários, serão analisados aspectos de governança e de ação coletiva.

\section{REFERENCIAL TEÓRICO}

\subsection{Governança}

A diversidade de conceitos e o uso amplo e geral da expressão governança tornam ainda mais necessária à construção de um referencial teórico consistente sobre o tema. O conceito de governança não se restringe aos aspectos gerenciais e administrativos do Estado, tampouco ao funcionamento eficaz do aparelho Estatal, refere-se, sim, a padrões de articulação e cooperação entre atores sociais e políticos e arranjos institucionais, que coordenam e regulam transações dentro e através das fronteiras do sistema econômico, incluindo-se aí não apenas os mecanismos tradicionais de agregação e articulação de interesses, tais como partidos políticos e grupos de pressão, como também redes sociais informais, hierarquias e associações de diversos tipos (SANTOS, 1997).

Um fator fundamental para a governança é a atuação do Estado, já que afeta os custos de produção e de transação em uma economia. As regras institucionais em uma democracia são definidas pelo poder legislativo, as disputas são resolvidas no poder judiciário e o poder executivo tem o papel de garantir sua implementação, assim. falhas do Estado, como, por exemplo, a insegurança jurídica, geram desincentivos para a produção, geram valor não explorado, dificultam a realização dos contratos. Em suma, aumentam os custos de transação da sociedade (ZYLBERSZTAJN, 2014).

Compreender os padrões de articulação e cooperação entre atores sociais no âmbito dos projetos de desenvolvimento rural, bem como os arranjos institucionais que o cercam é fundamental para avaliar seus resultados e seu desenvolvimento. A visão sistêmica nos mostra que os projetos de apoio à agricultura familiar, cofinanciados pelo Banco Mundial no Estado do Pará, estão inseridos em um sistema econômico do qual fazem parte agentes com transações específicas e instituições diferenciadas conforme cada realidade local, não sendo 
possível analisar os projetos do Pará Rural sem compreender o meio que os cercam, suas instituições e as relações entre os atores.

Entende-se que, no processo de construção do Pará Rural e suas inter-relações com os demais atores, o governo assume o papel de articulador do desenvolvimento local, incentivando a promoção de ações conjuntas em prol de benefícios coletivos. No entanto, a análise do resultado final obtido, qual seja, a verificação se houve melhoria da renda através de atividades produtivas, deve ser feita sob a ótica da governança dos Arranjos Produtivos Locais -APLs, elemento fundamental no desenvolvimento das atividades produtivas.

\subsection{Ação Coletiva}

O Programa Pará Rural tem como característica peculiar o financiamento coletivo, propondo-se, para tal, a apoiar associações ou cooperativas formalmente constituídas. Considerando a importância da gestão dos bens oriundos dos projetos pela comunidade como um todo, o investimento em infraestrutura produtiva para os cooperados beneficiados necessita também ser analisado sob a ótica da ação coletiva, visando compreender como se dá o uso desses recursos comuns.

Na década de 1960, Garret Hardin publicou seu trabalho denominado a Tragédia dos Comuns, em que faz um exame crítico da relação homem/natureza, afirmando que os recursos comuns estariam condenados a um uso excessivo e a um esgotamento se não fosse feita sua privatização ou gestão pelo mercado de trocas (SABOURIN, 2010).

Ainda de acordo com Hardin, quando um recurso natural renovável é utilizado por um coletivo, sem restrições na entrada, sem restrições no uso e sem custos para os usuários, este recurso será sobre-explorado, levando à Tragédia dos Comuns. Esta colocação se fundamenta em dois pontos: i) o crescimento da população mundial aumenta a pressão sobre os aludidos recursos e ii) o regime de propriedade comum favorece a sobre-exploração dos recursos naturais (BALLESTEROS; ALCOFORADO, 2009).

Em contraponto às ideias de Hardin e considerando uma análise crítica da Tragédia dos Comuns e da Teoria dos Jogos, Elinor Ostrom, na década de 90, afirma que, para atender as situações de interdependência entre atores heterogêneos, a ação coletiva é implementada com o uso das instituições.

Assim, a ação coletiva depende da capacidade de elaboração e adaptação de regras comuns, cuja existência dentro de um grupo constitui um estímulo à cooperação e ao compartilhamento (SABOURIN, 2010). As motivações para o estudo dos comuns por parte 
de Ostrom envolvem o contraste entre os seres humanos como sendo guiados quase que exclusivamente por interesses próprios, em oposição à preocupação com os outros e com a sociedade (OSTROM, 1990).

Ostrom se apoia analiticamente na categoria instituições, verificando o efeito da introdução de regras, associadas a mecanismos de controle e a sanções. Os resultados positivos mostram que, ao contrário do cenário apresentado por Hardin, cujas opções se baseiam no Estado ou no mercado, existe uma terceira via para evitar a tragédia: a gestão comunitária (LAURIOLA, 2009).

Em consonância com as análises de Ostrom, não há cooperação sem reciprocidade, ou seja, sem retorno ou sem compartilhamento por parte dos usuários, explicando a confiança mútua esta reciprocidade, considerada uma norma moral internalizada ou um princípio de troca social, caracterizado pela vontade de cooperar. Assim, os indivíduos obtêm melhores resultados, construindo condições em que a reciprocidade, a confiança e a reputação contribuam para superar ou reduzir os interesses egoístas (SABOURIN, 2010).

Outro elemento fundamental identificado por Ostrom foi à comunicação. Em seus estudos, foram utilizadas técnicas de economia experimental aplicadas à gestão de recursos comuns para testar as previsões do modelo "tragédia", envolvendo também o dilema do prisioneiro. Os resultados mostraram ser a comunicação elemento chave para evitar a tragédia, possibilitando procedimentos de aprendizagem, inerentemente coletivos, que permitem alcançar melhores resultados (LAURIOLA, 2009).

Assim, compreender como os elementos da ação coletiva tais como confiança, cooperação, reciprocidade e comunicação ocorrem nos projetos estudados nesta pesquisa é de fundamental importância para os entendimentos não só dos seus resultados, mas também de como as relações de governança são construídas.

\subsection{Instituições}

Com relação aos aspectos institucionais, Douglass North inicia sua análise econômica buscando entender os mecanismos que estruturam as relações sociais. O fundamental passa a ser a compreensão de que sem instituições não há intercâmbio político, social e econômico. As instituições reduzem as incertezas inerentes à interação humana, fornecendo, por conseguinte, os incentivos para a cooperação. Dependendo do tipo de cooperação social estabelecido, é possível ter incentivos maiores ao crescimento ou à estagnação econômica no longo prazo (AGUILAR FILHO, 2009). 
Ao analisar a experiência da Itália Moderna, Putnam (1996) afirma que as instituições são mecanismos para alcançar propósitos e não apenas para alcançar acordo. No estudo em questão, este autor se baseia num modelo de governança pautado em demandas sociais $\rightarrow$ Interação política $\rightarrow$ governo $\rightarrow$ opção de política $\rightarrow$ implementação, em que as instituições governamentais recebem subsídios do meio social e geram reações a esse meio.

A vertente do chamado novo institucionalismo econômico tem sua perspectiva compreendida em três partes principais: o ambiente institucional, a governança, representada pelas organizações, e o indivíduo como ator racional. O conjunto de regras do ambiente institucional estabelece as bases para a produção, o intercâmbio e a distribuição, moldando formas contratuais. A governança se apoia na definição de arranjos institucionais entre unidades econômicas e se refere à forma como essas unidades cooperam ou competem. As dimensões críticas do indivíduo são comportamentais e se referem à racionalidade limitada e ao oportunismo (CARVALHO; VIEIRA; GOULART, 2005).

Instituições são "regras do jogo", normas e valores que orientam a conduta do dia a dia e de orientações que reduzem a certeza dos indivíduos. Segundo a visão de Douglass North, o papel do mercado deve ser visto não apenas pela ideia abstrata de mecanismo de formação dos preços, mas como processo histórico que reflete poder, estruturas, convicções, normas e controles sociais. E em se tratando da relação entre organizações e ambiente institucional, por um lado as organizações são moldadas pelo ambiente, por outro elas que respondem pela transformação deste ambiente (ABRAMOVAY, 2001).

Uma instituição é resultado de um processo de institucionalização que envolve uma tipificação de ações tomadas como habituais por tipos específicos de atores. Estas ações se referem a comportamentos que se desenvolveram empiricamente e foram adotados por um ator ou grupo de atores a fim de resolver problemas recorrentes (TOLBERT; ZUCKER, 1996).

A formação da institucionalização envolve a habituação, que é o desenvolvimento de comportamentos padronizados para a solução de problemas, e a associação de tais comportamentos a estímulos particulares e a objetivação é que compreendem o desenvolvimento de significados socialmente compartilhados ligados a esses comportamentos. Neste contexto, a teoria institucional oferece um repertório de perspectivas e abordagens para explicar a estrutura das organizações (TOLBERT; ZUCKER, 1996).

Projetos que envolvem a participação de múltiplos atores e a governança com arranjos densos, tendo como referência o acerto entre eles, pressupõem a adoção de um desenho 
institucional que favoreça estas relações. Os interesses e ações coletivas, portanto, também condicionam as regras e desenhos institucionais de projetos, programas e políticas públicas, dando um caráter particular, segundo o grupo social que o implementa (FREITAS; CKAGNAZAROFF; FREITAS, 2014).

Neste sentido, o desenvolvimento de projetos rurais deve se alinhar à base institucional preexistente na comunidade, no município e na região, já que a cooperativa também molda e é moldada pelas instituições que a cercam.

\section{O PROGRAMA PARÁ RURAL}

O Programa de Redução da Pobreza e Gestão dos Recursos Naturais do Pará (Pará Rural) foi desenhado pelo Governo do Estado do Pará focado em duas áreas críticas, consideradas prioridades para o Estado: a redução da pobreza rural e o melhoramento da gestão dos recursos naturais (PARÁ RURAL, 2014).

O Programa é uma proposta político-estratégica do Estado do Pará, cofinanciada pelo Governo do Estado do Pará (GEP) e Banco Mundial (BIRD), no valor total previsto de US\$ 100.000.000,00, tendo como área de abrangência geográfica o ambiente rural do Estado.

Este programa se propõe a atuar em duas frentes convergentes de ação: a primeira, relacionada ao aumento da renda e melhoria das condições de vida de comunidades rurais pobres, pela implementação de projetos produtivos e provisão de infraestrutura complementar à produção; segunda, direcionada ao fortalecimento e aprimoramento do processo de gestão fundiária e ambiental do Estado, por investimentos na melhoria da estrutura institucional responsável pelo ordenamento territorial (PARA RURAL, 2014).

No que se refere ao componente A - investimento produtivo, objeto de análise deste trabalho, o Pará Rural visava o financiamento coletivo (para associações e cooperativas) para famílias de produtores rurais de bens e de serviços, dos quais, pelo menos, 70\% com renda média familiar igual ou inferior à linha da pobreza - R\$ 5.580,00/ano na época. Tem como meta o financiamento de aproximadamente 40 Projetos de Investimento Produtivo - (PIPs) em atividades produtivas agrícolas e não agrícolas, atividades de processamento e de comercialização e em infraestrutura complementar, além do custeio das atividades de capacitação, recuperação de áreas alteradas e manejo e conservação dos recursos naturais. $\mathrm{O}$ PIP abrange os investimentos necessários ao fortalecimento das cadeias e/ou arranjos

produtivos locais, por meio de ações que promovam o planejamento, a organização e a comercialização da produção, incluindo a prestação de serviços de assistência e capacitação 
técnica aos produtores, além de pequenas obras de infraestrutura complementar, necessárias para apoiar a geração de renda. O Pará Rural iniciou suas atividades em 2007 e tem prevista a finalização da primeira etapa em 2015 (PARA RURAL, 2014).

\section{DESENHO INSTITUCIONAL PARA A GOVERNANÇA}

Um programa voltado para financiamentos coletivos de atividades produtivas e redução da pobreza rural na Amazônia tem em seu próprio tema uma alta complexidade e um grande desafio para sua execução. O Manual Operacional do Programa (MOP) destaca como premissas da estratégia de atuação a participação popular na construção do processo (PARÁ RURAL, 2014).

Vale destacar que, após o processo de democratização no Brasil, que ocorreu em meados da década de 1980, os incentivos à participação política determinaram uma nova dinâmica de relacionamento entre o Estado e a Sociedade Civil, tendo as políticas públicas passado a incluir em seu desenho institucional a participação da sociedade civil nas decisões sobre as formas e possibilidades de investir em recursos públicos (CKAGNAZAROFF, 2014).

Desse modo, a indução à participação começou a integrar as exigências de diversos projetos de desenvolvimento aplicados ao meio rural, estimulando o surgimento de organizações coletivas. No entanto, em várias iniciativas, algumas organizações surgem apenas para viabilizar o acesso a recursos e benefícios. Tendo como premissa esta evidência, uma preocupação latente é a capacidade transformadora dessa organização no local em que emerge (CKAGNAZAROFF, 2014).

Ao analisar a governança é importante destacar que não se trata de uma ação isolada da sociedade civil buscando mais espaços de participação e influência, ao contrário, o conceito compreende a ação conjunta de Estado e Sociedade civil na busca de soluções e resultados para problemas comuns (GONÇALVES, 2005). A participação da sociedade civil em ações governamentais como o Programa Pará Rural deve ser planejada e detalhada de tal forma que garanta benefícios para os atores.

Um dos eixos de atuação do Programa é a criação de capital social, pelo fortalecimento das organizações comunitárias, influenciando na capacidade de construção e participação dos parceiros nas tomadas de decisão e responsabilidades, além de gerenciar os recursos públicos (PARA RURAL, 2014). 
Embora o Programa assuma como estratégia a participação da sociedade civil, o desenho institucional não deixa claro quais mecanismos serão adotados para que isso aconteça. Tendo vista essa lacuna do Manual, a implementação dessa estratégia passa a depender do gestor, tornando-se personalizada e individualizada, não garantindo que seja alcançada.

Por outro lado, há diferentes correntes teóricas que abordam o planejamento estratégico formal versus estratégia como prática. Junior (2014) lança uma possibilidade para o planejamento estratégico formal, diante das abordagens atuais, já que, por meio de suas pesquisas, ele percebeu que o planejamento formal pode fazer parte do cotidiano do praticante da estratégia nos diversos níveis hierárquicos, desde que se pense nele como um discurso que detém uma relação com um processo cognitivo (interpretações) e com a ação (execuções objetivadas, funcionais) (JUNIOR, 2014).

Assim, embora o desenho institucional não deixe claro de que forma se dará a estratégia de participação da comunidade, é possível que a estratégia ocorra na prática. O importante é que, independentemente da discussão entre a interpretação de uma estrutura (como o planejamento formal) ou de uma agência (a prática), temas determinantes como a participação em Programas de Redução da Pobreza rural devem fazer parte do cotidiano de pensar e agir estrategicamente.

Ao tratar do arranjo institucional do Programa, o Manual Operacional descreve que este arranjo se baseia em uma estrutura matricial, envolvendo o concurso dos diferentes agentes públicos, estaduais e municipais, entidades não governamentais e associações de produtores (PARA RURAL, 2014). No entanto, ao detalhar a estrutura básica e descrever as atribuições dos participantes, o Programa se limita a detalhar os papéis de apenas quatro agentes, que são aqueles ligados diretamente ao Governo do Estado, como a Direção Geral do Programa, o Núcleo de Gerenciamento, a Secretaria de Meio Ambiente e o Instituto de Terras.

Merece destaque nesta discussão o papel do Estado quando se fala em governança. Para melhor compreensão, é válido relembrar que Governança é a capacidade governativa no sentido amplo, envolvendo a capacidade de ação estatal na implementação das políticas e na consecução das metas coletivas. Refere-se ao conjunto dos mecanismos e procedimentos para lidar coma dimensão participativa e plural da sociedade, o que implica expandir e aperfeiçoar os meios de interlocução e de administração do jogo de interesses (DINIZ, 1998)

O desafio envolve superar a dicotomia Estado-mercado, implica um novo estilo de gestão pública e um novo padrão de articulação Estado-sociedade, reformulando as práticas mais convencionais de administração pública. Através da criação de oportunidades e incentivos 
introduzidos por novos arranjos institucionais, é possível conduzir a formação e o modo de atuação dos grupos na direção almejada. Esse resultado, vale insistir, não pode ser alcançado aleatoriamente, envolvendo, ao contrário, o acionamento de instrumentos que viabilizem a inserção do Estado na sociedade. Aqui também são reveladas a obsolescência dos antigos desenhos institucionais e a atualidade dos mecanismos que reduzam a defasagem governantes-governados (DINIZ, 1998).

Para assegurar a participação da sociedade civil nas decisões do Pograma, existe o Comitê Gestor, criado pelo Governo do Estado, através do Decreto 1.646, de 11 de maio de 2009, que tem por responsabilidade a aprovação final de Projetos de Investimentos Produtivos a serem financiados pelo Pará Rural. Trata-se de um órgão colegiado, de deliberação coletiva, integrado por representantes do Estado, nomeados pelo Governo do Estado, e membros da sociedade civil, indicados pelas organizações/entidades que representam, ratificados pelo Governo do Estado (PARÁ RURAL, 2014).

Além de órgãos ligados ao governo do Estado, a sociedade civil participa do Comitê através de representantes da Federação dos Trabalhadores na Agricultura no Pará e Federação dos Trabalhadores na Agricultura Familiar no Pará. O Comitê devera se reunir ordinariamente a cada dois meses (PARÁ RURAL, 2014).

As instituições como mecanismos que estruturam as relações sociais devem ser compreendidas objetivando entender a realidade do local onde o projeto é implantado e suas peculiaridades. É de grande valia a instância de validação em um Comitê Gestor, porém são fundamentais também validações locais com base nos atributos institucionais e na realidade de cada projeto.

Em um Estado com as dimensões geográficas do Pará e diferentes realidades regionais, as diversidade de particularidades locais devem ser consideradas sempre que se tratar de projetos de desenvolvimento. Em se tratando de políticas públicas que envolvem um conjunto de atores envolvidos em um processo participativo, alguns elementos determinantes devem ser considerados, tais como a vontade e o comprometimento político do governo, a tradição associativa local e a dinâmica institucional resultante das articulações entre o Estado e a sociedade (FREITAS; CKAGNAZAROFF; FREITAS, 2014). 


\section{A COMUNIDADE MENINO JESUS NO MUNICÍPIO DE ACARÁ}

A Comunidade Menino Jesus recebeu financiamento do Programa Pará Rural para a construção de uma casa de farinha mecanizada e uma unidade de beneficiamento de frutas para a venda de polpas congeladas. O projeto englobava, incialmente, 204 famílias quilombolas.

A pesquisa de campo ocorreu três meses após a conclusão das unidades de beneficiamento previstas no projeto. Foi aplicado um questionário semiestruturado ao presidente da cooperativa, à equipe de cooperados responsável pela administração do empreendimento e à funcionária administrativa contratada para apoiar a gestão. Também foi possível adotar o método de observação participante, estando presente, inclusive, em uma reunião da cooperativa com técnicos do Pará Rural para tratar do projeto.

No que se refere à governança, durante os levantamentos, foram mapeadas as organizações com as quais a comunidade transaciona, distribuídas em três categorias: Órgãos governamentais, Produção e ONGs, Universidades e atores coletivos. A categoria dos Órgãos governamentais foi aquela que teve o maior número de organizações, com oito instituições listadas, sete delas ligadas ao governo estadual (Pará Rural, Núcleo Quilombola da Casa Civil, Secretaria de Meio Ambiente, Instituto de Terras do Pará, Agência de Defesa Agropecuária do Pará, Empresa de Assistência Técnica e Extensão Rural do Pará e Secretaria de Estado de Saúde do Pará), e ao Poder público municipal, foi listada a Secretaria de Agricultura do Município. Nenhum órgão federal foi listado pela comunidade.

Nota-se que o papel do Estado como articulador da governança do projeto se deu em sua maioria no esfera do poder públco estadual, apoiando a obtenção de parcerias especialmente com órgãos afins. A comunidade avaliou com nível de confiança alto $71 \%$ dos órgãos estaduais e apenas um teve sua avaliação considerada ruim.

Vale destacar que a governança local envolve um ambiente institucional em que o governo cria tipos de relacionamentos com os atores que incentivem o lançamento e a sustentação de iniciativas de desenvolvimento. No entanto, para a criação do sistema de governança local, é necessária a contribuição de todos os outros componentes do sistema (ATKINSON, 2002). 
Foi citada a nessidade de apoio maior da prefeitura municipal através da secretaria de agricultura, e ao descreverem o relacionamento esperado e ocorrido com o Programa Pará Rural, os membros da comunidade disseram que esperavam maior participação, já que o Núcleo Gestor do Programa foi responsável por todas as contratações e execução do projeto.

É fundamental envolver a comunidade nos desenhos dos projetos e, em vez de importar ou imitar modelos existentes, as estratégias devem ser personalizadas e o conteúdo devidamente localizado para oferecer os benefícios destinados aos beneficiários rurais (MALHORTA; CHARRU; CHARIAR, 2006).

O desafio está em elaborar um modelo de negócios para o desenvolvimento rural, mesclando parcerias coletivas e incorporadas ao conhecimento tradicional, garantindo o envolvimento e a apropriação dos próprios beneficiários rurais (MALHORTA; CHARRU; CHARIAR, 2006).

Ao tratar da ação coletiva, merece destaque o relatado feito pelos membros da comunidade quanto à ausência de regras de uso dos bens comuns, apesar de durante a aplicação do questionário ter sido informado que parte das regras já haviam sido definidas. A ausência de regras e sanções faz com que haja conflitos e muitas dúvidas quanto à utilização dos recursos produtivos. Foi mencionado como fator de grande dificuldade a esse processo o baixo nível de escolaridade dos membros da comunidade.

\section{Conclusões}

Para que a boa governança ocorra, constituindo uma rede a favor do desenvolvimento em Projetos de apoio à agricultura familiar, é necessário um desenho institucional favorável. A forma como o arranjo de governança se estrutura é decisiva. $\mathrm{O}$ desenho institucional do Programa Pará Rural aborda aspectos de governança de forma superficial, sem indicar possíveis ações e responsáveis, deixando a critério do gestor a implementação ou não de uma estratégia eficaz para a consolidação de possíveis arranjos que favoreçam os projetos.

O desenho institucional do Programa Pará Rural, materializado em seu Manual Operacional, aborda aspectos de governança de forma superficial, sem indicar possíveis ações e responsáveis, deixando a critério do gestor a implementação ou não de uma estratégia eficaz para a consolidação de possíveis arranjos que favoreçam os projetos. Dessa forma, o papel do Estado como articulador de políticas públicas fica vulnerável a entendimentos pessoais e 
mudanças políticas. Para a garantia da participação e da governança, o Programa, desde a sua concepção, deve inserir no desenho operacional forma e instrumentos que orientem como se dará a participação da comunidade em todo o processo.

Há diversos elementos intrínsecos e extrínsecos à comunidade que devem ser observados anteriormente e durante a implantação de projetos de desenvolvimento rural. Os arranjos que podem ser constituídos para viabilizar uma estratégia de desenvolvimento dependem de aonde aquela comunidade quer chegar, necessitando, antes de mais nada, que ela saiba que caminho deseja seguir.

O uso adequado do bem coletivo resultado do projeto depende, sim, da cooperação e da reciprocidade, mas também das regras e sanções e especialmente da capacidade que esta comunidade terá de construir e validar essas regras.

Por fim, se recomenda que projetos de apoio à agricultura familiar analisem anteriormente a ação coletiva da comunidade, os possíveis arranjos que podem se constituir, alinhados à estratégia local e às diferentes condições sistêmicas (sociais, econômica, culturais, institucionais e participativas). Tais análises não devem ser feitas com o objetivo de serem excludentes, mas, sim, de potencializar a ação dos projetos e trazer ainda mais benefícios à comunidade.

\section{REFERÊNCIAS BIBLIOGRÁFICAS}

ABRAMOVAY, R., Desenvolvimento e instituições: a importância da explicação histórica. In: ARBIX, Glauco; ZILBOVICIUS, Mauro \& ABRAMOVAY, Ricardo (orgs.). Razões e ficções do desenvolvimento. São Paulo, Edunesp/Edusp, pp. 165-177. 2001

AGUILAR FILHO, H. A. O Institucionalismo de Douglas North e as Interpretações Weberianas do Atraso Brasileiro. PhD thesis, PPGE/UFRGS. 2009.

ARAUJO, M. C. Capital Social. Rio de Janeiro: Jorge Zahar Ed., 2003.

ATKINSON,D. Local Government, Local Governance and Sustainable Development: Getting the Parameters Right ,HSRC, Cape Town, 2002

BALlESTEROS, VHM; ALCOFORADO, I. Tragédia dos Commons e os direitos de propriedade: Com Hardin, além de Hardin. VIII Encontro da Sociedade Brasileira de Economia Ecológia. Cuiabá - MT. Ago 2009

CARVALHO, C.; VIEIRA, M.; GOULART, S. A trajetória conservadora da teoria institucional .RAP, v. 39, n. 4, p. 849-874, 2005 
CKAGNAZAROFF, I. B. et al., Governança em planejamento e Desenvolvimento local: uma análise teórica. Revista de Ciências Humanas, Vol. 8, No 2, p. 171-191, Jul./Dez. 2008

DINIZ, E. . Governabilidade, "Governance" e Reforma do Estado: Considerações Sobre o Novo Paradigma. XX Encontro Anual da ANPOCS, Caxambu, Minas Gerais. 1998

FREITAS, A. F.; CKAGNAZAROFF, I. B. ; FREITAS, A. Uma análise do desenho institucional do projeto de combate da pobreza rural em Minas Gerais, Brasil Agroalimentaria, vol. 20, núm. 38, enero-junio, 2014, pp. 151-166 Universidad de los Andes. Mérida, Venezuela

GEREFFI, G.; HUMPHREY, J.; STURGEON, T. The governance of global value chains. Review of International Political Economy pg 78-104. February 2005

Gil, A. C. Métodos e técnicas de pesquisa social - 6. ed. - São Paulo : Atlas, 2008.

GONÇALVES, A.F. O conceito de governança. In: CONGRESSO NACIONAL CONPENDI, 14. 2005, Fortaleza. Anais... Fortaleza, 2005. Disponível em: http://www.conpedi.org.br/manaus/arquivos/Anais/Alcindo\%20Goncalves.pdf.

LAURIOLA, V. Elinor Ostrom: um nobel heterodoxo e rosa-verde. Sinal de esperança? Boletim da Sociedade Brasileira de Economia Ecológica, Brasilia, n. 21, p. 3-8, 2009.

MALHORTA, CHARRU, CHARIAR ,V.M., DAS, L.K. ICT for Rural Development: An Inclusive Framework for e-Governance. Adopting e-Governance, p. 216-222, 2007

MARANTE, L. A Reconstrução do Sentido de Comunidade: Implicações Teóricas Metodológicas no Trabalho sobre a Experiência do Sentido de Comunidade. Dissertação de Mestrado. Faculdade de Psicologia, Universidade de Lisboa. 2010

OliVEIRA, C. M.; SANTANA, A. C. A Governança no Arranjo Produtivo de Grãos de Santarém e Belterra, Estado do Pará: uma análise a partir do grão soja. RESR, Piracicaba - SP, Vol. 50, No 4, p. 683-704, Out/Dez 2012.

OLIVEIRA, D. Manual de Gestão das Cooperativas: Uma abordagem prática. 21. ed. São Paulo: Atlas, 2001

OSTROM, E. Governing the Commons: The Evolution of Institutions for Collective Action. Cambridge: Cambridge University Press, 1990.

PARÁ RURAL- Programa de Redução da Pobreza e Gestão dos Recursos Naturais do Pará. Volume I - Concepção e Implementação do Programa. Janeiro de 2014. Disponível em http://www.pararural.pa.gov.br/documentos.php.

PUTNAM, R. Comunidade e democracia: a experiência da Itália Moderna. - Rio de Janeiro: Fundação Getúlio Vargas, 1996.

SABOURIN, E. Manejo dos recursos comuns e reciprocidade: os aportes de Elinor Ostrom ao debate. Sustentabilidade em Debate, Brasília, v. 1, n. 2, p. 143-158, 2010. 
SANTOS, M. C. Governabilidade, governança e democracia: criação de capacidade governativa e relações executivo legislativo no Brasil pós-constituinte. Dados, Rio de Janeiro, v. 40, n. 3, 1997

SANTOS, F. S. Capital social: vários conceitos, um só problema. São Paulo: Fundação Getúlio Vargas, 2003.

SILVA, E. L; MENEZES, E. M. Metodologia da pesquisa e elaboração de dissertação. Florianópolis: Laboratório de Ensino a Distância da UFSC, $3^{\text {a }}$ ed. rev., 2002.

SUZIGAN, W.; FURTADO, J.; GARCIA, R. Estruturas de governança em arranjos ou sistemas locais de produção. Gestão da Produção, São Carlos, v. 14, n. 2, p. 425-439, maio/ago. 2007.

TOLBERT, P.; ZUCKER, L. G. The institutionalization of institutional theory. In: CLEGG, S. R.; HARDY, C.; NORD, W. R. (Eds.). Handbook of organization studies. London: Sage Publications, p. 175-190. 1996.

VILPOUX, O. Desempenho dos arranjos institucionais e minimização dos custos de transação: transações entre produtores e fecularias de mandioca. Rev. Econ. Sociol. Rural; Brasília, vol.49, nº.2, p. 271-294, 2011.

ZYLBERSTAJN, D. Coordenação e Governança de Sistemas Agroindustriais. In: Antônio Márcio Buainain; Eliseu Alves; José Maria da Silveira; Zander Navarro. (Org.). O mundo rural no Brasil do século 21. 1 ed. Brasília: v. 1, p. 267-294, 2014

Submetido em: 14/03/16

Aceito em : 21/06/16 